\title{
COATING PROCESS OF CORN GRAINS USING TREATMENT MACHINE WITH BRUSH SCREW CONVEYOR
}

\author{
Alexandru Zaica, Alexandra Visan, Ana Zaica, Mihai Olan, George Bunduchi \\ National Institute of Research-Development for Machines and Installations \\ Designed to Agriculture and Food Industry, Romania \\ zaica_alexandru@yahoo.com
}

\begin{abstract}
After the harvesting process, agricultural products (grains, fruits, vegetables, etc.) cannot be used directly for different purposes such as: preservation, consumption, industrialization, marketing, sowing, etc.) Prior to receiving a particular destination, it is necessary and obligatory for the harvested products to undergo preparatory operations on conditioning and quality control in order to meet different uses. In order to improve grain health and to avoid production decline and quality worsening due to the attack of diseases and pests transmitted through grains, treatment has long been used for some species and generalizes rapidly with better results of seed treatment by various means - physical, chemical or biological. Success in grain crops begins with efficient seed treatment, so one of the criteria for assessing the seed quality is its chemical treatment with major implications for the development of future crops. The development of an appropriate technology for the treatment of cereal seeds and technical plants requires a thorough analysis of all the factors involved in the chemical treatment of the seeds (seed quality, their destination, particularities of seed conditioning according to the variety, particularities of the equipment used). The paper presents experimental research results conducted on a machine with brush screw conveyor, which allowed the variation of operating parameters that are graphically represented. The testing methodology for treatment equipment has been developed according to the construction features and functional parameters. Therefore, we determine the interdependence between the coverage degree and the functional parameters that were tested and we formulate recommendations for the use of these types of machines.
\end{abstract}

Keywords: corn grains, treatment process, screw conveyor machine.

\section{Introduction}

Coating of grains is used to improve handling and for the delivery of protectants, symbiotic microorganisms, micronutrients, soil adjuvants, germination promoters, growth regulators, and colours [1].

The use of high physiological quality grains in agriculture is among one of the best practices for obtaining maximum crop yields all over the world. These seeds are more likely to achieve a high performance when exposed to different environmental conditions, expressed in a high percentage and speed of emergence, good stand establishment, good initial seedling development [2] and increased final production. After sowing seeds are still exposed to biotic and abiotic environmental factors [3] and agricultural soils have a lot of pathogenic microorganisms that can interact with grains and seedlings [4], and can reduce their performance causing grain rot, seedling death or root rot [5].

For example, 'Phytophagous insects' in the soil can also damage seedlings [6] and significantly reduce the plant population. There are few studies that discuss the influence of polymer treatment substances used in grain treatment related to seed physiological quality and performance of many species, both for crop establishment in the field and during storage. However, there is a lack of information on how the different treatment substances interact with the physical seed properties of different species and with the different products used for seed treatment.

Grains may vary in their sensitivity to the physical sanitation treatments, not only between species, but also between the same grain lots from the same crop and variety.For optimisation of the treatments, a series of pre-tests are performed to determine the parameters optimal for treatment of the respective grain lot, but the experience has shown that grain lots stored for the same period of time and having the same moisture content may still vary in their sensitivity towards the thermal and chemical treatment [7-9].

Complex machines and equipment are used to perform grain treatment, which are composed mainly of one system rotating disc for spreading of the substance and one screw conveyor with brush for better uniformity of the coating substance on the grain surface.

This paper tries to present the variation of the main parameters contributing to the coverage degree and some preliminary experimental researches tested on mobile grain treatment with a rotary 
disc and a screw conveyor with brush to identify optimal work for this type of machine to obtain a higher coverage degree.

\section{Materials and methods}

The research and the experimental activities were performed using a machine that was designed and produced at INMA Bucharest, Fig. 1. The grains used in laboratory tests were hybrid corn grains of Syngenta Genetics variety. The grains used were previously cleaned, sorted, calibrated and after that the humidity content $(14 \%)$ was established.
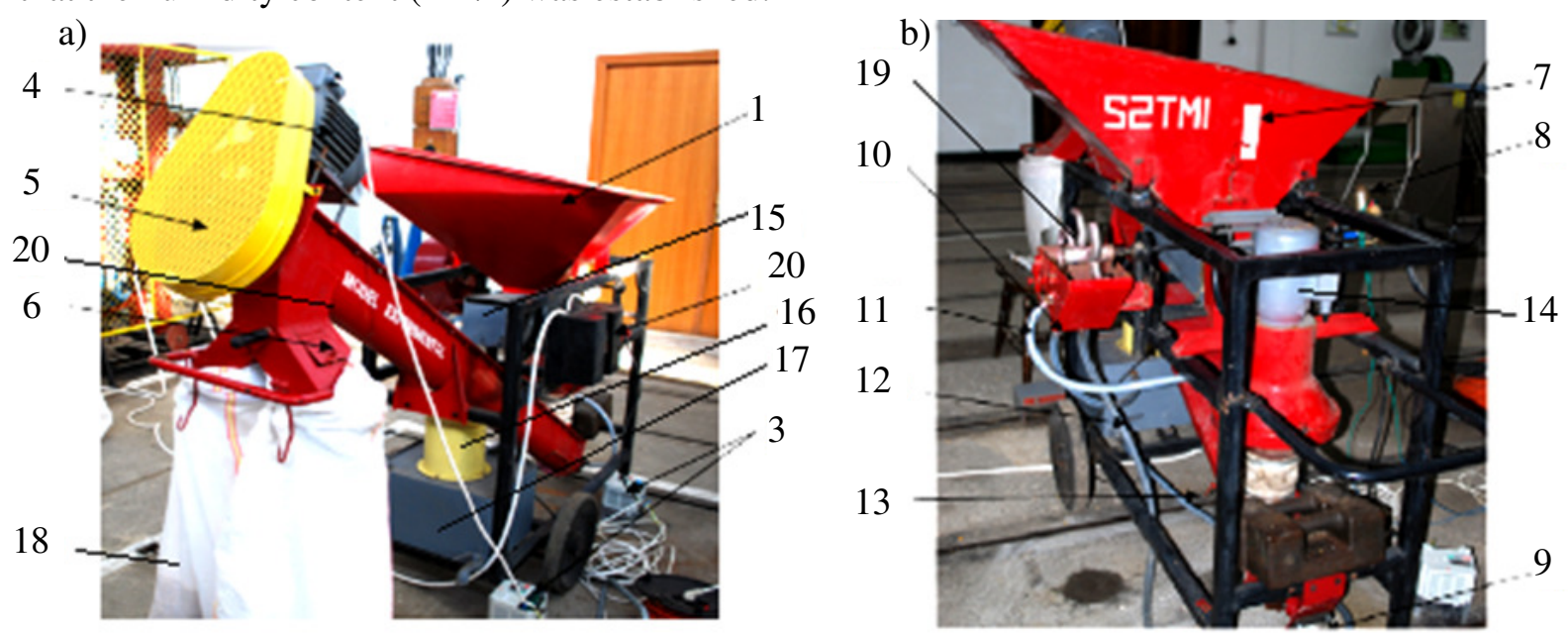

Fig. 1. Grain treatment machine: $\mathrm{a}$ - right side view; $\mathrm{b}$ - left side view; 1 - hopper; 2 - control panel switch ON/OFF; 3 - speed control converters; 4 - screw conveyor motor;5 - protective housing for chain transmission; 6 - evacuation holes bag; 7 - adjustment for corn supply; 8 - drive system of the dosing mechanism;9 - liquid feed pump;10 - recovery liquid hose; 11 - liquid drum supply;12 - liquid dispenser supply;13 - fluid power hose pump.14 - cone electric motor; 15 - vibrating table; 16 - solution mixing system; 17 - solution tank; 18 - treated corn bag; 19 - dosing system: 20 - brush conveyor

Cleaned, sorted or calibrated grains come through free fall into the hopper. Below the hopper a vibratory feeder is mounted to keep the plant working capacity constant. The grains to be treated at the output of the vibratory feeder are dispersed on the outer surface of the inner cone of the spray drum. From inside the cone the liquid is finely atomized with a spreader disc at a speed of $3000 \mathrm{rpm}$. The liquid used for grain treatment is sent by the pump into the adjustable level vessel, whereupon with the help of a special dozer it reaches the spraying drum.

The excess liquid in the dispenser is returned to the liquid reservoir where it is pumped again and recycling. The operation of the pump is simultaneous with the operation of the brush conveyor screw. These rayon fibre brushes are designed to uniformity of the film to be treated, formed on the surface of the grain, and to transport the product to the upper end of the gutter where it is discharged through two holes bag that works alternately [10].
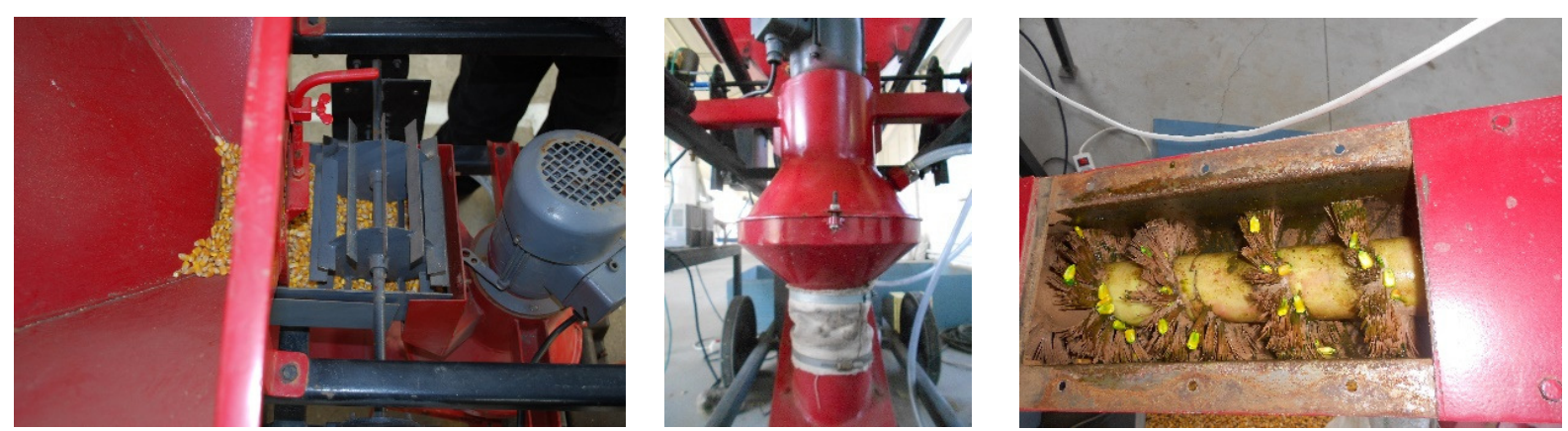

Fig. 2. Details of grain treatment installation: a - top view rotary cone;

$\mathrm{b}$ - front view rotary cone; $\mathrm{c}-$ section screw conveyor with brushes 
In Fig 2.a we have the feed hopper provided at the bottom with an adjusting mechanism, which ensures uniform flow of seeds. In Fig 2.b we have a drum with a sprayer, inside the scraper disc is mounted, coupled to an electric motor, what ensures that the liquid to be treated is sprayed on the corn surface. In Fig 2.c we see the section, where the solution film is applied over the entire surface of the grain.

The testing methodology for the treatment machine has been developed according to the construction features and functional parameters (grain flow rate, he substance flow rate, rotation speed of drum , screw conveyor rotational speed) and it required the use of specific equipment for carrying out tests (Fig 3).

a)

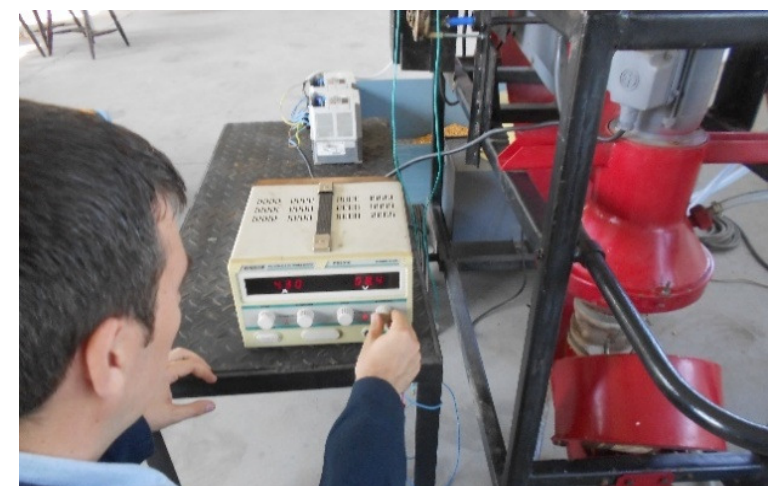

b)

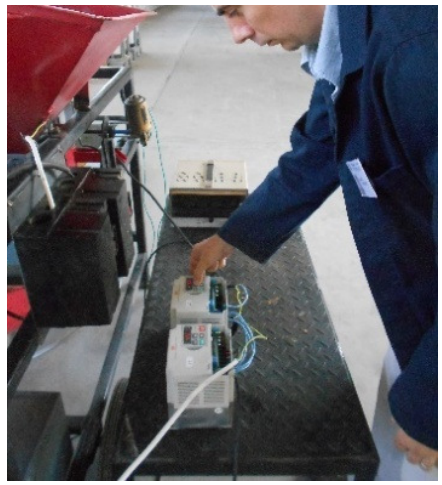

Fig. 3. Aspects during parameter setting: $a$ - disk drum speed variation; $b$ - screw conveyor speed

As not all parameters have a high influence in the experiments, measurements for just a few of them were performed.

In this sense determinations were made with corn pursuing the variation of the main parameters:

- grain flow rate $Q, \mathrm{~kg} \cdot \mathrm{s}^{-1}$;

- treatment substance flow rate $Q_{l}, 1 \cdot \min ^{-1}$;

- rotation speed of $n_{r s c d}$, rev $\cdot \mathrm{min}^{-1}$;

- $\quad$ screw conveyor rotational speed $n_{t e}$, rev $\cdot \mathrm{min}^{-1}$;

- grain treatment degree $G_{a f}, \%$;

Degree of covering $\left(G_{a f}\right)$ is determined by the harvest samples and visual analysis in the laboratory, using the following formula used in "International Seed Testing Standards":

$$
G_{a f}=(N T G / N G T) \times 100 \%,
$$

where $\quad N T G-$ number of treated grains;

$N G T$ - number of total grains.

During the experiments the liquid concentrate Vitavax $200 \mathrm{FF}$ (no color liquid) was used, on which a color green pigment (tartrazina E 102 + brilliant blue FCF E 133) was added in order to evaluate the seed covering degree.

A grain is considered treated, if it has the outer surface covered at least $90 \%$ treated with chemicals [11].

The determination was made on at least 500 grains and is repeated at least 3 times, the result is the arithmetic mean of the measurements.

\section{Results and discussion}

Processing the experimental data obtained under laboratory conditions (determined by direct or indirect methods) there is a series of values that are centralized and represented in the following graphs.

In Table 2 the values are listed for the position of the liquid flow adjusting system of the liquid. Meeting the manufacturer's specifications for the substance for treatment it was used in the experiments. 
Experimental data for three control positions of the fluid dispenser

\begin{tabular}{|c|c|c|c|c|c|}
\hline $\begin{array}{l}\text { No. } \\
\text { crt. }\end{array}$ & $\begin{array}{l}\text { Dosing system } \\
\text { speed, rev } \cdot \text { min }^{-1}\end{array}$ & $\begin{array}{c}\text { Minimum } \\
\text { solution flow } \\
Q_{l \text { min }}, 1 \cdot \text { min }^{-1} \\
\end{array}$ & $\begin{array}{c}\text { Maximum } \\
\text { solution flow } \\
Q_{l \text { max }}, 1 \cdot \text { min }^{-1} \\
\end{array}$ & $\begin{array}{c}\text { Average solution } \\
\text { flow per pipe } \\
Q_{l p}, l \cdot \text { min }^{-1} \\
\end{array}$ & $\begin{array}{c}\text { Average } \\
\text { solution flow } \\
Q_{\text {lav }}, \text { l } \cdot \text { min }^{-1} \\
\end{array}$ \\
\hline 1 & 5 & 0.15 & 0.96 & 0.158 & 0.948 \\
\hline 2 & 10 & 0.35 & 1.22 & 0.224 & 1.344 \\
\hline 3 & 15 & 0.6 & 1.40 & 0.285 & 1.714 \\
\hline
\end{tabular}

Experimental data for disk drum speed

Table 2

\begin{tabular}{|c|c|c|c|c|c|}
\hline \multirow{2}{*}{$\begin{array}{c}\text { No. } \\
\text { crt }\end{array}$} & $\begin{array}{c}\text { Converter } \\
\text { working } \\
\text { frequency, Hz }\end{array}$ & \multicolumn{2}{|c|}{ Disk drum speed, rev· $\mathbf{m i n}^{-\mathbf{1}}$} & \multirow{2}{*}{ Rean value, rev· $\mathbf{m i n}^{-\mathbf{1}}$} \\
\cline { 3 - 5 } & 10 & 599 & 601 & 601 & 600 \\
\hline 1 & 20 & 1201 & 1200 & 1199 & 1200 \\
\hline 2 & 30 & 1805 & 1803 & 1812 & 1800 \\
\hline 3 & 40 & 2409 & 2413 & 2407 & 2400 \\
\hline 5 & 50 & 2998 & 3000 & 2999 & 3000 \\
\hline
\end{tabular}

In Table 3 and Table 4 the experimental values are listed obtained at the drum disk and the screw conveyor with the help of 2 converters and a tachometer. The nominal engine speed is $1410 \mathrm{rpm}$ and the chain drive action with 19-wheel drive wheel, driven wheel 95, transmission ratio 1/5.

Table 3

Experimental data for screw conveyor speed

\begin{tabular}{|c|c|c|c|c|c|}
\hline \multirow{2}{*}{$\begin{array}{c}\text { No. } \\
\text { crt. }\end{array}$} & $\begin{array}{c}\text { Working } \\
\text { frequency } \\
\text { converter, Hz }\end{array}$ & \multicolumn{2}{|c|}{ Screw conveyor speed, rev min $^{-1}$} & \multirow{2}{*}{$\begin{array}{c}\text { Approx. mean value, } \\
\text { rev } \text { min }^{-1}\end{array}$} \\
\hline 1 & 10 & 47.7 & 52.5 & 1 & 10 \\
\hline 2 & 20 & 89.8 & 105.2 & 2 & 20 \\
\hline 3 & 35 & 172.4 & 182.7 & 3 & 35 \\
\hline 4 & 40 & 204.3 & 215.3 & 4 & 40 \\
\hline 5 & 50 & 267.3 & 278.5 & 5 & 50 \\
\hline
\end{tabular}

In Table 4 the raw material flow is presented in accordance with the hoper position on the feeding bunker. The data presented have a logical correlation and from the technologic process point of view can be easily compared with other equipments.

Table 4

Experimental data for feed rate

\begin{tabular}{|c|c|c|c|c|}
\hline No. crt. & Hopper feeding position & Grain mass, $\mathbf{~ k g}$ & Time, $\mathbf{s}$ & Grain flow, $\mathbf{~ k g} \cdot \mathbf{s}^{-1}$ \\
\hline 1 & D1 & 35 & 121.5 & 0.288 \\
\hline 2 & D2 & 35 & 101.7 & 0.344 \\
\hline 3 & D3 & 35 & 82.2 & 0.426 \\
\hline
\end{tabular}

In Fig. 4 it can be seen that the degree of coating of the grains with the suspension varies depending on the speed of the helicoidal conveyor and inversely proportional to the feed rate of the grains. For this, the variation is quite constant at the feed rates of up to $0.35(\mathrm{~kg} / \mathrm{s})$, and after this variation, the coefficient of coverage increases exponentially.

For $3000\left(\mathrm{rev} \cdot \mathrm{min}^{-1}\right)$ of the screw conveyor the covering degree increases considerably for flows smaller then $0.35\left(\mathrm{~kg} \cdot \mathrm{s}^{-1}\right)$ with at least 10 units and the distribution uniformity can be clearly seen, Fig. 5. So, to obtain a covering of almost $100 \%$, it is indicated to increase the rotational speed of the centrifugal drum distributor. 
Due to the large number of attempts made and the multitude of the parameters involved in the process of grain treatment with this type of equipment the diagrams representative of the process without taking into account the quadratic relationship without data errors will be presented.

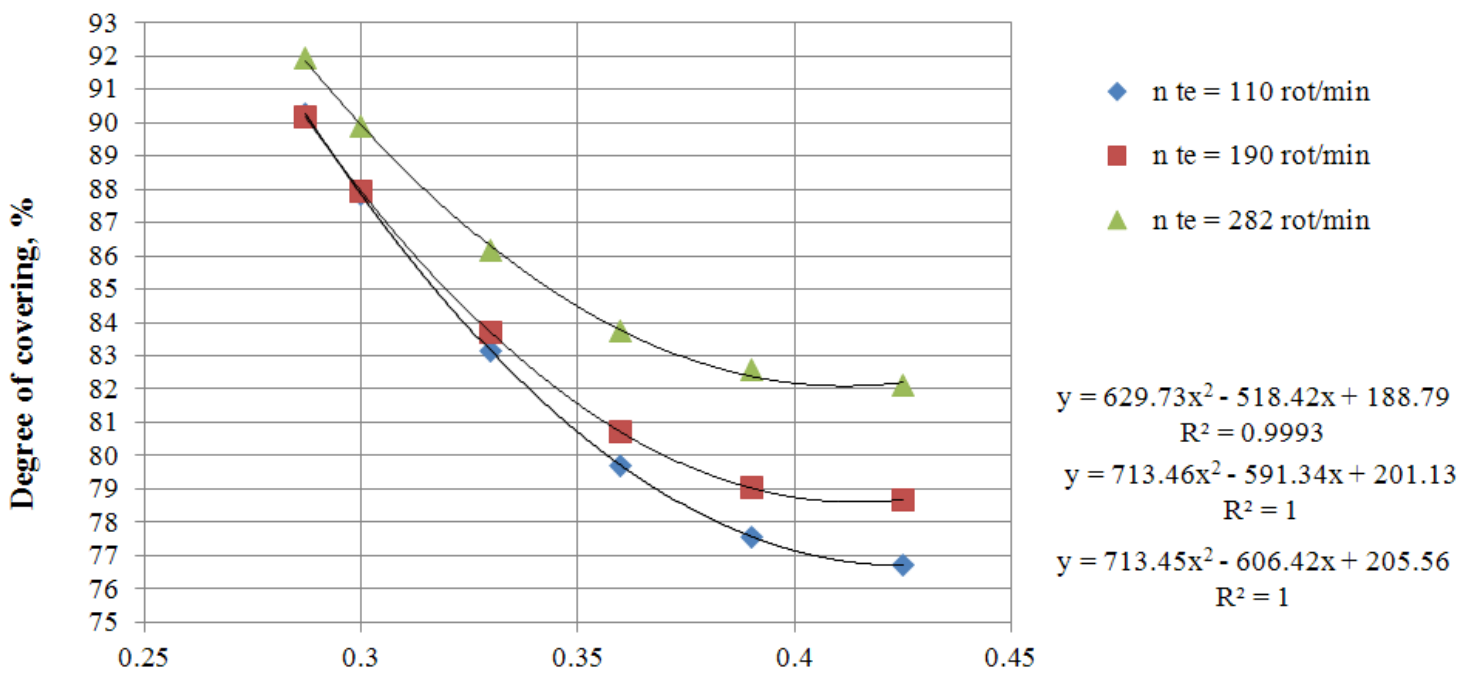

Seed flow, $\mathrm{kg} \cdot \mathrm{s}^{-1}$

Fig. 4. Evolution diagram of covering degree depending on grain flow at $n_{r s c d}=2000 \mathrm{rev} \cdot \mathrm{min}^{-1}$

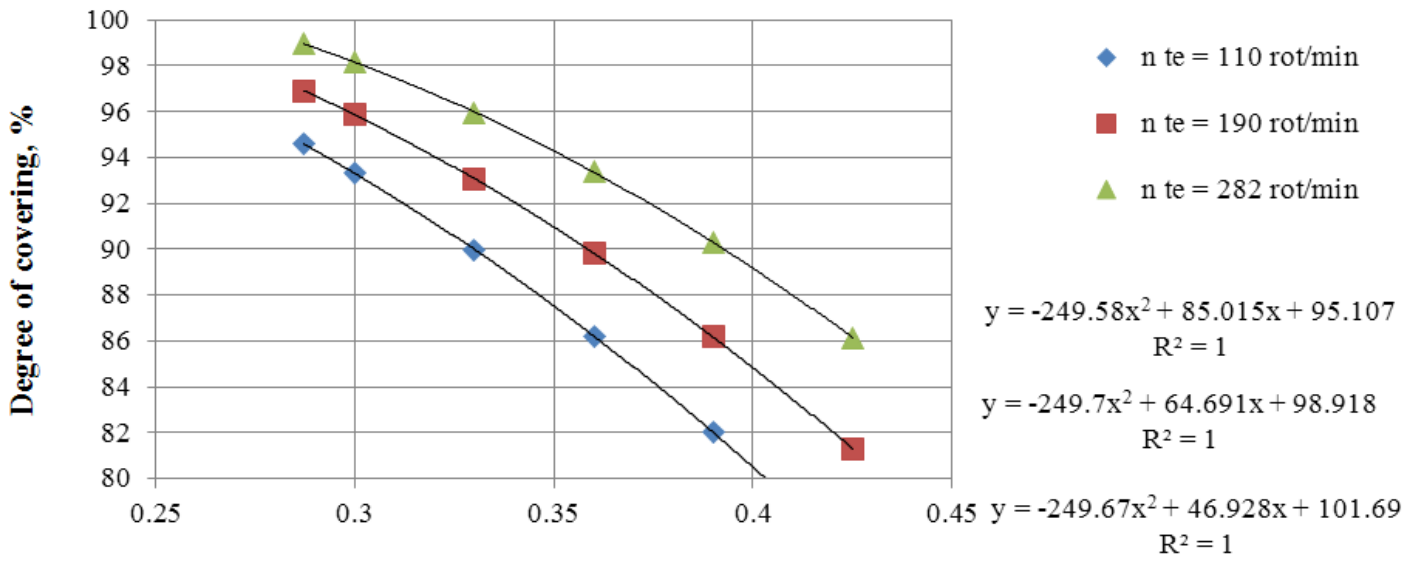

Seed flow, $\mathrm{kg} \cdot \mathrm{s}^{-1}$

Fig. 5. Evolution diagram of covering degree depending on grain flow at $n_{r s c d}=3000 \mathrm{rev} \cdot \mathrm{min}^{-1}$

In Fig.6, there are samples of corn grain presented at the outlet from the brush screw conveyor that were divided into the categories, respectively untreated (Fig 6.a), where the grains do not have the required percentage of the substance and treated grains (Fig 6.b) in accordance with the experimental methodology.

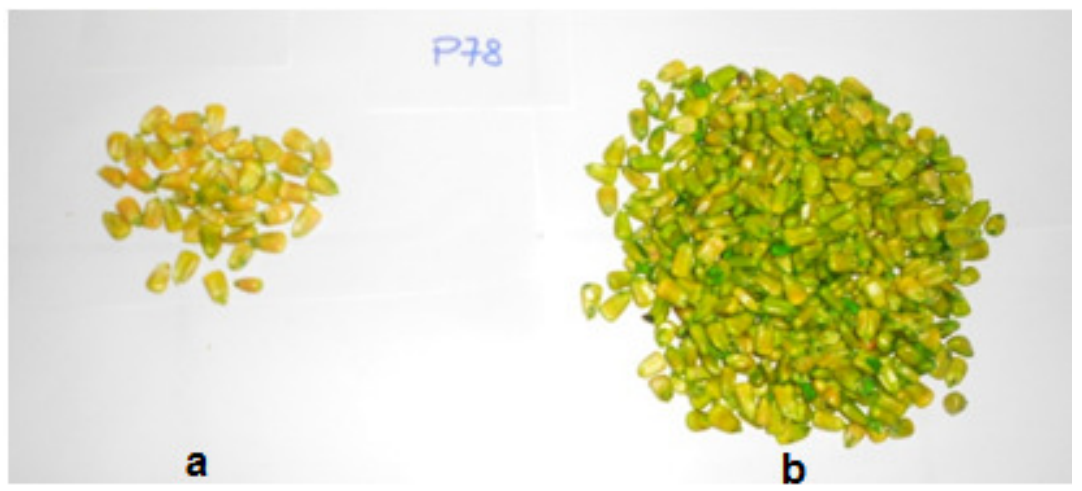

Fig. 6. Samples from untreated and treated corn grains 


\section{Conclusions}

1. As experimental researches in the field of grain treatment equipment with an inclined screw conveyor brush are quite few and in literature enough data cannot be found regarding the influence of constructive elements on the covering degree, this paper comes to completing the experimental research and support further researchers in this field.

2. All operating parameters influence the final grain treatment degree and they must be carefully adjusted in order to optimize the treatment precision according to the substance and the manufacturer's indications.

3. During the experimental activity interdependence was noticed between two main bodies that contribute to grain treatment to achieve a high coverage degree. They are, the spreading disc from the conical drum and the brush screw conveyor.

4. The presented data are important for the researchers of this field of activity and exploiters of these types of grain processing and conditioning, referring primarily to the operation of the technological process of grain treatment.

\section{Acknowledgements}

This work was supported by a grant of the Romanian Research and Innovation Ministry, through Programme 1 - Development of the national research-development system, subprogramme 1.2 Institutional performance - Projects for financing excellence in RDI, contract No. 16PFE.

\section{References}

[1] Avelar S., Baudet L., Villela F. The improvement of the seed treatment process,Seed News 2009, vol. XIII,no.5, pp.8-11;

[2] Fellows P.J. Food processing technology: Principles and practice (Second edition), Woodhead Publishing Limited,Cambrige England, June 2000;

[3] Johansson K., Kennedy B. W., Quintom M. Prediction of breeding values and dominance effects from mixed models with approximations of the dominance relationship matrix,April 1993Livest Prod Sci vol.34, issues 3-4, pp. 213-223;

[4] Kunkur V., Hunje R., Patil N.K.B., Vyakarnhal B.S. Effect of seed coating with polymer, fungicide and insecticide on seed quality in cotton during storage, Karnataka Journal of Agricultural Sciences2007, vol.20, n.1, pp.137-139;

[5] Suemar A.G.A; FabianneValéria de Sousa; Guilherme F; Leopoldo B; Silmar T.P., The use of film, Londrina2012;

[6] Girolami V.,Mazzon L.,Squartini A., Mori N.,Marzaro M., Di Bernardo A.,Greatti M.,Giorio C.,Tapparo A., Translocation of neonicotinoid insecticides from coated seeds to seedling guttation drops: a novel way of intoxication for bees, Journal of Economic Entomology2009,vol.102, no.5, pp.1808-1815.

[7] Groot SPC., Birnbaum Y.,RopN.,JalinkH., Forsberg G.,KromphardtC.,Werner S.,KochE., Effect of seed maturity on sensitivity of seeds towards physical sanitation treatments, Seed Science and Technology 2006, no.34, pp. 403-413;

[8] Tillmanm M.A.A., Miranda D.M., Análise de sementes. In: PESKE. S.T., LUCCA FILHO, O.A., BARROS, A.C.S.A. (Ed.).Sementes: fundamento scientíficos e tecnológicos, 2006Pelotas: UFPel, pp.159-255;

[9] Walsh J., Rooney K. Canestrino J. Seed coating Innovations, Proceedings California/Nevada Alfalfa Symposium, 3-4 December 1998, pp. 209-210;

[10]Zaica A., Visan A.L., Paun A., Gageanu P., Bunduchi G., Zaica A., Stefan V., Manea D., The coating process of corn grains using a treatment machine with brush screw conveyor, Proceedings of the 44th International Symposium on Agricultural Engineering: Actual Tasks on Agricultural Engineering, Opatija, Croatia, 23-26 February 2016, pp. 333-345.

[11] ISTA International Seed Testing Standards (sampling). 